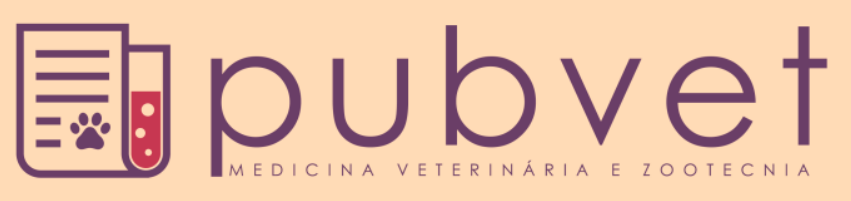

https://doi.org/10.22256/pubvet.v12n4a69.1-7

\title{
Degradabilidade do capim-marandu manejado sob pastejo por vacas suplementadas ou não com óleo de soja
}

\author{
Francyelle Ruana Faria da Silva ${ }^{\ominus}$, Giovanna Araújo Carvalho $^{\ominus}{ }^{2}$, Pedro Gomes da \\ Cruz $^{3}$, Ana Karina Dias Salman ${ }^{\ominus}$, Eduardo Schimtt ${ }^{\ominus} 4$
}

${ }^{I}$ Mestranda no Programa de Pós-graduação em Ciências Ambientais - PGCA/UNIR. Rolim de Moura, Rondônia, Brasil. E-mail: franruana@ gmail.com ${ }^{2}$ Mestranda no Programa de Desenvolvimento Regional eMeio Ambiente, UNIR, bolsista CAPES, Porto Velho, Rondônia, Brasil.E-mail: giovanna.carvalhozootec@ gmail.com ${ }^{3}$ Pesquisador(a) da Empresa Brasileira de Pesquisa, Porto Velho, Rondônia, Brasil.E-mail: pedro-gomes.cruz@embrapa.br, ana.salman@embrapa.br

${ }^{4}$ Professor adjunto da Universidade Federal de Pelotas, Pelotas, RS, Brasil. E-mail: schmitt.edu@gmail.com

* Autor para correspondência

\begin{abstract}
RESUMO. O objetivo deste trabalho foi avaliar o efeito da suplementação concentrada com ou sem óleo de soja sobre a degradabilidade da matéria seca (MS), fibra em detergente neutro (FDN) e fibra em detergente ácido (FDA) do capim-marandu manejado sob pastejo intermitente com dois dias de ocupação e 28 dias de descanso e taxa de lotação de 2,6 UA/ha. Foi realizado um ensaio de degradabilidade in situ utilizando três vacas secas canuladas no rúmen mestiças $3 / 4$ Gir x $1 / 4$ Holandês em delineamento crossover $3 \times 3 \mathrm{com}$ três tratamentos: sem suplementação (NS); suplementação concentrada sem óleo de soja (SO); e suplementação concentrada contendo $7 \%$ de óleo de soja (CO). Os períodos de incubação foram de $0,6,12,36,48$ e 96 horas. Não houve diferença estatística entre os tratamentos. Os valores da degradabilidade potencial da MS, da FDN e da FDA do capim nos animais nos tratamentos NS, SO e CO foram: $81,80 \%, 92,12 \%$ e $91,54 \% ; 56,05 \%$, $58,60 \%$ e $60,21 \% ; 60,01 \%, 64,34 \%$ e $65,17 \%$, nessa ordem. A suplementação com concentrado contendo ou não $7 \%$ de óleo de soja não altera os parâmetros de degradação ruminal do capim-marandu.
\end{abstract}

Palavras chave: ruminantes, suplementação lipídica, Urochloa brizantha

\section{Degradability of Marandu grass under grazing by cows supplemented or not with soybean oil}

\begin{abstract}
This work aimed to evaluate the effect of supplementation with concentrate containing or not soybean oil on rumen degradation of dry mater (DM), neutral detergent fiber (NDF) and acid detergent fiber (ADF) of Marandu grass managed with occupation period of two days with 28 days of rest and 2.6 AU/ha of stocking rate. An in situ trial was carried out with three dry crossbred 3/4 Gyr x 1/4 Holstein rumen cannulated cows arranged in $3 \times 3$ crossover design with three treatments: no supplementation (NS), supplementation with non-soybean oil concentrate (NO), supplementation with $7 \%$ soybean oil concentrate (SO). Incubation periods were $0,6,12,36,48$ and 96 hours. There was no difference among treatments. The values of potential degradability of DM, NDF and ADF of marandu-grass determined in animals from NS, NO and SO were: $81.80 \%, 92.12 \%$ and $91.54 \% ; 56.05 \%$, $58.60 \%$ and $60.21 \% ; 60.01 \%, 64.34 \%$ and $65.17 \%$, respectively. Supplementation with concentrate containing or not $7 \%$ of soybean oil do not change rumen degradation parameters of marandu-grass.
\end{abstract}

Keywords: lipid supplementation, ruminant, Urochloa brizantha 


\title{
Degradabilidad del pasto Marandu manejado bajo pastoreo por vacas suplementadas o no con aceite de soja
}

\begin{abstract}
RESUMEN. Este trabajo se realizó con el fin de evaluar el efecto de la suplementación concentrada con o sin aceite de soja sobre la degradabilidad de la materia seca (MS), fibra en detergente neutro (FDN) y fibra en detergente ácido (FDA) del Capin Marandu manejado bajo pastoreo intermitente con dos días de ocupación y 28 días de descanso y tasa de capacidad de 2,6 UA / ha. Se hizo un ensayo de degradabilidad in situ con el uso de tres vacas secas con cánulas en el rumen mestizas $3 / 4$ Gir x $1 / 4$ Holandés en delineamiento crossover $3 \times 3$ con tres tratamientos: sin suplementación (NS); suplementación concentrada sin aceite de soja (SO); y suplementación concentrada que contenía $7 \%$ de aceite de soja (CO). Los períodos de incubación fueron de 0, 6, 12, 36, 48 y 96 horas. No ocurrió diferencia estadística entre los tratamientos. Los valores de la degradabilidad potencial de MS, FDN y FDA del pasto en los animales en los tratamientos NS, SO y CO fueron: $81,80 \%, 92,12 \%$ y $91,54 \% ; 56,05 \%, 58,60 \%$ y $60,21 \% ; 60,01 \%, 64,34 \%$ y $65,17 \%$, en ese orden. La suplementación con concentrado que contenía o no el $7 \%$ de aceite de soja no modificó, ni alteró los parámetros de degradación ruminal del capim marandu.
\end{abstract}

Palabras clave: rumiantes, suplementación lipídica, Urochloa brizantha

\section{Introdução}

O conhecimento da degradabilidade ruminal das diferentes frações dos alimentos permite balancear as rações de forma a maximizar a produtividade do animal e minimizar os custos com alimentação (Van Soest, 1994, Berchielli et al., 2011, Valadares Filho et al., 2016), já que o potencial de aproveitamento dos nutrientes da dieta é um dos fatores que mais exerce influência na resposta do animal em produção.

Vacas leiteiras de alta produção exigem dietas de melhor valor nutricional, pois os processos metabólicos responsáveis pela produção de leite são altamente dependentes da disponibilidade de proteína e energia no rúmen (NRC, 2001). A suplementação com lipídeos, como óleo de soja nas rações de vacas leiteiras, principalmente no período de transição é uma alternativa para elevar o nível energético da dieta, sem aumentar a consumo de ração (Salla et al., 2003), podendo ainda influenciar positivamente na reprodução (Ghasemzadeh-Nava et al., 2011). No entanto, visto que a alimentação natural dos ruminantes tem por base as forragens, e estas apresentam baixo teor de lipídios (geralmente em torno de 3\% da MS), a inclusão de níveis muito elevados de óleo nas rações pode apresentar efeitos negativos e inibitórios na fermentação ruminal (Kozloski, 2011), comprometendo a digestibilidade dos nutrientes (NRC, 2001, Vargas et al., 2002),

O objetivo deste trabalho foi avaliar a degradabilidade da matéria seca (MS), da fibra em detergente neutro (FDN) e da fibra em detergente ácido (FDA) do capim-marandu em pastejo por vacas suplementadas ou não com concentrado contendo óleo de soja.

\section{Material e Métodos}

O estudo foi realizado no campo experimental da Empresa Brasileira de Pesquisa Agropecuária Embrapa, em Porto Velho, Rondônia, Brasil. Conduziu-se um ensaio em delineamento crossover $3 \times 3$ com três tratamentos e três períodos experimentais de 14 dias, sendo 10 dias para adaptação à dieta e quatro dias para incubação ruminal. Os tratamentos foram: sem suplementação (NS); suplementação concentrada sem a inclusão de óleo de soja (SO); e suplementação concentrada contendo $7 \%$ de óleo de soja na matéria seca (CO) (Tabela 1).

Foram utilizadas três vacas não lactantes, mestiças 3/4 Gir x 1/4 Holandês, com peso vivo médio de $420 \pm 84,11 \mathrm{~kg}$, providas de cânulas no rúmen, as quais ficaram, durante todo o período experimental, em pastagem de capim Marandu manejada com lotação intermitente com dois dias de ocupação e 28 dias de descanso e taxa de lotação de 2,6 UA/ha.

O capim foi coletado pelo método de pastejo simulado conforme descrito por Prohmann et al. (2012). Após secagem em estufa de ventilação forçada a $65^{\circ} \mathrm{C} / 72$ horas, as amostras de capim foram moídas a $5 \mathrm{~mm}$ e acondicionadas em sacos de $5 \times 5 \mathrm{~cm}$ de tecido não tecido (TNT) número 100 $\left(100 \mathrm{~g} / \mathrm{m}^{2}\right)$ (Casali et al., 2008). Após a incubação nos tempos $0,6,12,36,48$ e 96 horas, os sacos 
foram retirados simultaneamente e lavados manualmente em água corrente. No tempo zero estimou-se a fração solúvel pela imersão das amostras em água a $39^{\circ} \mathrm{C}$ por 30 minutos. Todas amostras foram secas em estufa de ventilação forçada a $65^{\circ} \mathrm{C}$ por 72 horas e, após resfriadas em dessecador, foram pesadas.

Tabela 1. Proporção dos ingredientes e composição química das rações experimentais e do capim Marandu.

\begin{tabular}{|c|c|c|c|}
\hline $\begin{array}{l}\text { Ingredientes, \% } \\
\text { MS }\end{array}$ & $\begin{array}{c}\text { Ração } \\
\text { Controle }\end{array}$ & $\begin{array}{c}\text { Ração } \\
\text { Tratamento }\end{array}$ & $\begin{array}{c}\text { Capim } \\
\text { Marandu }\end{array}$ \\
\hline Farelo de soja & 43,75 & 48,78 & - \\
\hline Milho moído & 50,00 & 37,28 & - \\
\hline Sal mineral & 4,69 & 5,23 & - \\
\hline Ureia & 1,56 & 1,74 & - \\
\hline Óleo de soja & 0,00 & 6,97 & - \\
\hline Total & 100 & 100 & - \\
\hline \multicolumn{4}{|l|}{ Composição, \% } \\
\hline Matéria Seca & 88,29 & 88,11 & 29,51 \\
\hline Matéria Mineral & 9,94 & 8,05 & 5,49 \\
\hline Proteína Bruta & 31,32 & 31,50 & 8,08 \\
\hline Extrato Etéreo & 0,89 & 5,07 & 1,63 \\
\hline FDN & 10,20 & 10,70 & 59,77 \\
\hline FDA & 5,01 & 3,31 & 30,04 \\
\hline Lignina & 0,83 & 0,92 & 3,75 \\
\hline Celulose & 4,18 & 4,39 & 26,29 \\
\hline Hemicelulose & 5,19 & 5,39 & 29,73 \\
\hline${ }^{1} \mathrm{CT}$ & 57,85 & 55,38 & 84,80 \\
\hline${ }^{2} \mathrm{ED}(\mathrm{Mcal} / \mathrm{kg})$ & 3,66 & 3,53 & 2,77 \\
\hline${ }^{2} \mathrm{EM}(\mathrm{Macal} / \mathrm{kg})$ & 3,25 & 3,12 & 2,34 \\
\hline${ }^{2} \mathrm{NEl}$ (Mcal/kg) & 1,91 & 1,84 & 1,38 \\
\hline${ }^{3} \mathrm{NDT}$ & 83,10 & 80,18 & 62,86 \\
\hline DIVMS & 88,60 & 85,08 & 66,67 \\
\hline
\end{tabular}

MS: Matéria seca; FDN: Fibra em detergente neutro; FDA: Fibra em detergente ácido; $\mathrm{CT}=$ Carboidratos totais; $\mathrm{ED}=$ Energia digestível; EM = Energia metabolizável; $\mathrm{NEl=}$ Energia liquida; NDT $=$ Nutrientes digestíveis totais DIVMS: Digestibilidade in vitro matéria seca. ${ }^{1}$ Estimativa de acordo com Sniffen et al. (1992); ${ }^{2}$ Estimativa de acordo com NRC (2001); ${ }^{3}$ Estimativa de acordo com Valadares Filho et al. $\underline{(2016)}$.

Os resíduos de incubação foram analisados quanto aos teores de matéria seca (MS) em estufa a $105^{\circ} \mathrm{C}$ por 12 horas e quanto à fibra em detergente neutro (FDN) e fibra em detergente ácido (FDA) pelo método sequencial, utilizando o determinador de fibra TE-149 TECNAL $^{\circledR}$ Detmann et al. (2012).

A partir da fração solúvel em água (a) e do potencial de degradação da fração potencialmente degradável (b) da MS foi calculada a fração insolúvel como $100-(\mathrm{a}+\mathrm{b})$. A taxa de degradação (c) foi obtida pela regressão dos tempos de incubação sobre o peso dos resíduos de incubação transformado pelo logaritmo natural (ln), de modo a satisfazer o modelo de degradabilidade potencial proposto por Mehrez et al. (1977):

$\mathrm{DP}=\mathrm{a}+\mathrm{b}\left(1-\mathrm{e}^{-\mathrm{ct}}\right)$ para $\mathrm{t}>\mathrm{L}$

Onde:

$\mathrm{L}=$ tempo de colonização.

$\mathrm{a}=$ fração solúvel.

$\mathrm{b}=$ fração insolúvel potencialmente degradável.

$c=$ taxa constante de degradação da fração $b$.

As degradabilidades efetivas da MS, da FDN e da FDA foram estimadas levando-se em conta as taxas de passagem de 2, 5 e $8 \%$ por hora, as quais correspondem aos níveis de ingestão alimentar baixo, médio e alto, respectivamente, segundo preconizado pelo AFRC (1993), onde se utilizou a equação proposta por Ørskov \& McDonald (1979):

$\mathrm{DE}=\mathrm{a}+\mathrm{b} . \mathrm{c} /\left(\mathrm{c}+\mathrm{K}_{1}\right)$

Onde:

$\mathrm{a}=$ fração imediatamente solúvel.

$\mathrm{b}=$ fração insolúvel potencialmente degradável.

$\mathrm{c}=$ taxa constante de degradação da fração $\mathrm{b}$.

$\mathrm{K}_{1}=$ taxa de passagem no rúmen da fração sólida do conteúdo ruminal.

Os dados foram analisados pelo SAS (2004) (Statistical Analysis System) utilizando os procedimentos NLIN e GLM, e as médias das variáveis observadas em cada tratamento foram comparadas pelo teste t a 5\% de significância.

\section{Resultados e Discussão}

Não foram observadas diferenças $(\mathrm{P}>0,05)$ entre os tratamentos para os parâmetros de degradação da MS, FDN e FDA.

Ao comparar a degradação da matéria seca (MS) do capim Marandu em função dos períodos de incubação, verificou-se uma tendência de maior degradação nos animais suplementados a partir das 12 horas de incubação (Figura 1). $\mathrm{O}$ mesmo foi observado com a fibra (Figura 2 e 3 ).

Até às 12 horas os três tratamentos tiveram poucas variações de degradação, no entanto das 12 até às 96 horas de incubação os tratamentos com suplementação mantiveram-se semelhantes, porém com tendência de degradação levemente superior ao grupo não suplementado, sendo que em média, $80 \%$ da degradação nos três 
tratamentos ocorreram até às 48 horas de incubação.

De acordo Costa et al. (2015) a suplementação é uma fonte de nutrientes adicionais, com objetivo de suprir as deficiências nutricionais impostas pela baixa qualidade nutricional de forrageiras tropicais e possui a característica de apoiar a degradabilidade das frações fibrosas da planta.

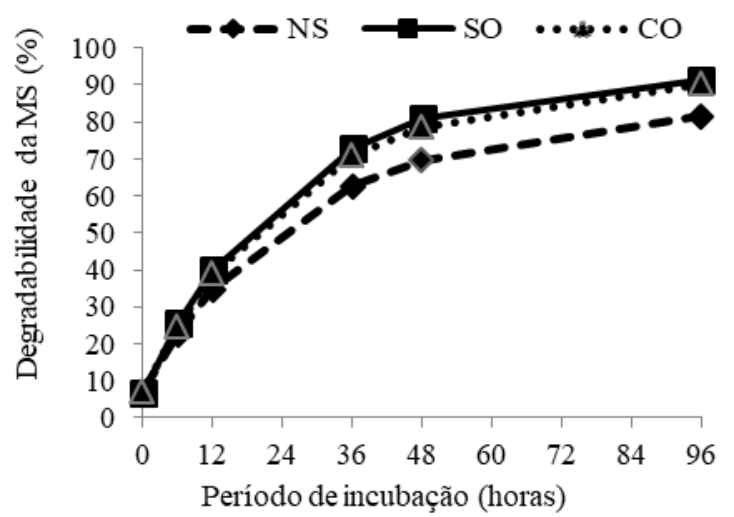

Figura 1. Degradabilidade da matéria seca (MS) do capim Marandu nos tratamentos sem suplementação (NS); suplementação concentrada sem óleo de soja (SO); e suplementação concentrada contendo $7 \%$ de óleo de soja (CO), em função do período de incubação no rúmen de vacas leiteiras.

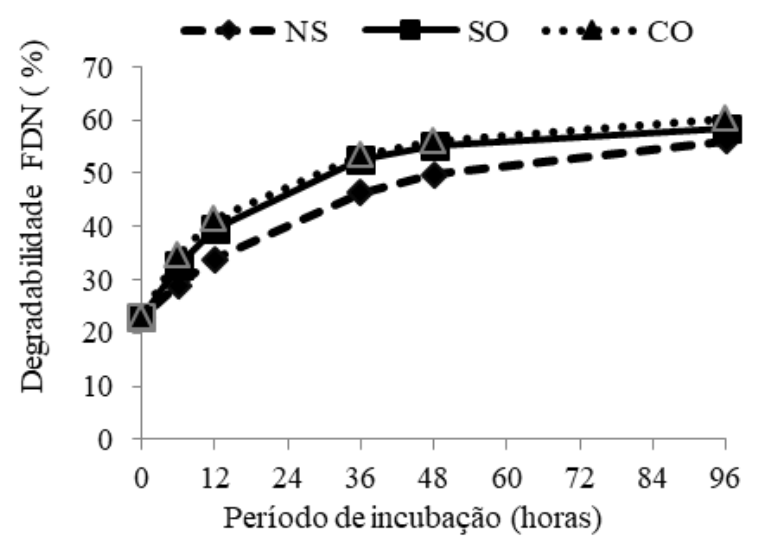

Figura 2. Degradabilidade da fibra em detergente neutro (FDN) do capim Marandu nos tratamentos sem suplementação (NS); suplementação concentrada sem óleo de soja (SO); e suplementação concentrada contendo $7 \%$ de óleo de soja $(\mathrm{CO})$, em função do período de incubação no rúmen de vacas leiteiras.

Segundo Reis et al. (2009), quando se supre as necessidades de PB pela suplementação concentrada aumenta-se a eficiência de degradação da fração fibrosa e, consequentemente, a taxa de passagem e o consumo de matéria seca da forragem.

Os parâmetros "a", "b" e "c" e as degradabilidades potenciais (DP) e efetiva (DE) da MS, para taxas de passagem de 2,5 e $8 \% / h$, são apresentados na Tabela 2. Considerando que apenas a alimentação dos animais diferia, a fração solúvel (a) do capim foi a mesma para todos os tratamentos $(6,8 \%)$.

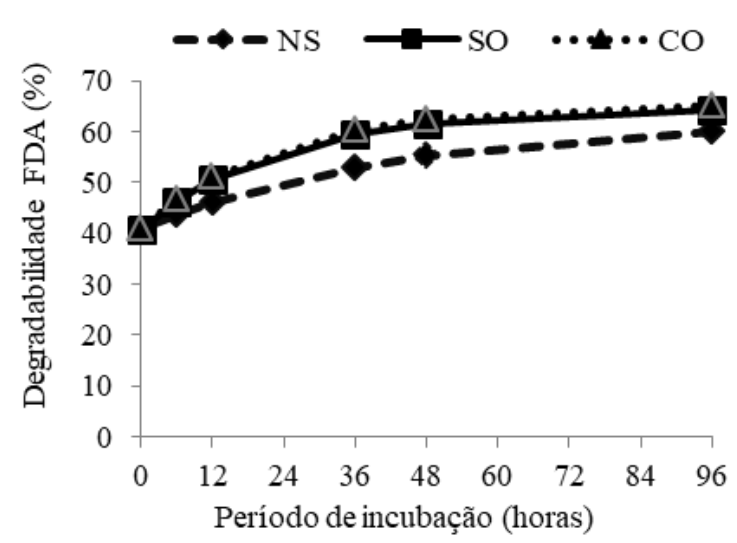

Figura 3. Degradabilidade da fibra em detergente ácido (FDA) do capim Marandu nos tratamentos sem suplementação (NS); suplementação concentrada sem óleo de soja (SO); e suplementação concentrada contendo $7 \%$ de óleo de soja (CO), em função do período de incubação no rúmen de vacas leiteiras.

Araújo et al. (2016) ao avaliarem a degradabilidade da matéria seca da folha do capim Marandu em monocultivo no período das chuvas observaram fração "b" (54,3\%) e "c" $(2,2 \%)$ inferiores e DE 5\%/h (45,5\%) semelhantes as encontradas no presente estudo. Costa et al. (2015) ao avaliarem a silagem do capim Marandu encontraram DE da matéria seca $(35,8 \%, 26,8 \%$ e $23,7 \%$ considerando taxa de passagem de 2,5 e $5 \% / \mathrm{h}$, respectivamente) consideravelmente inferiores aos valores encontrados nesse estudo.

Rodrigues et al. (2004) trabalharam com três acessos de $B$. brizantha cortada aos 42 e 63 dias e observaram valores de 66,1 a $94,4 \%$ para a degradabilidade potencial (DP) da MS, 1,5 a $4,6 \% / \mathrm{h}$ para a taxa de degradação (c), e 43,0 a $55,7 \%$ e 31,0 a $42,8 \%$ para as DE calculadas, respectivamente, considerando-se taxas de passagem de 2 e $5 \% / \mathrm{h}$. Em outro trabalho realizado para comparar a degradabilidade ruminal da MS de $B$. brizantha cv. Marandu (5,8 a $9,7 \%$ de PB e 67,7 a $69,7 \%$ de FDN), obtida em sistema silvipastoril onde a gramínea estava sob sombreamento por arbóreas ou em pastagens manejadas em monocultivo, Moreira et al. (2009) relataram valores médios de 51,3 e $50,5 \%$; e 36,0 a $35,5 \%$ para DE calculadas, respectivamente, considerando-se taxas de passagem de 2 e $5 \% / \mathrm{h}$ no rúmen.

Goes et al. (2012) ao avaliarem a degradação ruminal da MS de volumosos para bovinos, 
encontraram para Brachiaria brizantha taxa constante de degradação $(4,4 \% / \mathrm{h})$ próxima as encontradas no presente estudo, no entanto as frações "a", "b" e DE 2, 5 e 8\%/h (41,4\%, 54,1\% e $34,9 \%$, respectivamente) consideravelmente diferentes.
As variações entre os resultados encontrados na literatura podem estar relacionadas a diversos fatores ligados ao animal, à planta, ao ambiente $\mathrm{e}$ ao manejo, tais como: sistema de criação adotado, dieta do animal, categoria animal, idade de corte da forrageira, além das peculiaridades de cada experimento.

Tabela 2. Degradabilidade potencial (DP), degradabilidade efetiva (DE) para taxas de passagem 2, 5 e $8 \% / h$, resíduo não degradável (C), fração insolúvel potencialmente degradável (B), taxa constante de degradação de B (c) e fração solúvel (A) do capim Marandu nos três tratamentos.

\begin{tabular}{|c|c|c|c|c|c|c|c|c|}
\hline & \multirow[b]{2}{*}{ DP } & \multicolumn{3}{|c|}{$\mathrm{DE}$} & \multirow[b]{2}{*}{$\mathrm{C}$} & \multirow[b]{2}{*}{$\mathrm{b}$} & \multirow[b]{2}{*}{$\mathrm{c}$} & \multirow[b]{2}{*}{$\mathrm{a}$} \\
\hline & & $2 \%$ & $5 \%$ & $8 \%$ & & & & \\
\hline \multicolumn{9}{|c|}{ Matéria Seca } \\
\hline$\overline{\mathrm{NS}}$ & 81,80 & 57,00 & 39,83 & 31,57 & 13,11 & 80,09 & 3,71 & 6,78 \\
\hline $\mathrm{SO}$ & 92,12 & 67,91 & 49,38 & 39,48 & 7,38 & 86,16 & 4,90 & 6,78 \\
\hline $\mathrm{CO}$ & 91,54 & 65,72 & 46,83 & 37,13 & 6,88 & 86,32 & 4,38 & 6,78 \\
\hline $\mathrm{CV} \%$ & 8,30 & 13,19 & 16,92 & 17,98 & 37,95 & 4,33 & 27,11 & 0,00 \\
\hline \multicolumn{9}{|c|}{ Fibra em detergente neutro (FDN) } \\
\hline NS & 56,05 & 43,73 & 35,71 & 32,16 & 41,69 & 35,38 & 3,10 & - \\
\hline $\mathrm{SO}$ & 58,60 & 47,48 & 40,12 & 36,25 & 40,72 & 36,35 & 5,69 & - \\
\hline $\mathrm{CO}$ & 60,21 & 51,49 & 43,81 & 39,57 & 38,72 & 38,35 & 6,69 & - \\
\hline $\mathrm{CV} \%$ & 8,23 & 10,08 & 12,31 & 12,70 & 10,75 & 11,83 & 53,35 & - \\
\hline \multicolumn{9}{|c|}{ Fibra em detergente ácido (FDA) } \\
\hline NS & 60,01 & 52,75 & 48,10 & 46,09 & 36,94 & 22,17 & 2,65 & - \\
\hline $\mathrm{SO}$ & 64,34 & 57,09 & 51,83 & 49,16 & 35,09 & 24,02 & 4,34 & - \\
\hline $\mathrm{CO}$ & 65,17 & 57,74 & 52,35 & 49,60 & 34,14 & 24,97 & 4,27 & - \\
\hline $\mathrm{CV} \%$ & 6,47 & 6,77 & 6,22 & 5,38 & 9,35 & 13,95 & 30,10 & - \\
\hline
\end{tabular}

NS = Não suplementados; $\mathrm{SO}=$ suplementação sem óleo de soja; $\mathrm{CO}=$ suplementação com óleo de soja; $\mathrm{CV}=$ coeficiente de variação. Médias seguidas de letras iguais nas colunas não diferem entre si pelo teste Tukey $(\mathrm{P}<0,05)$.

De acordo com o $\underline{\mathrm{NRC}(2001)}$ a redução da degradação é um dos indícios de que a suplementação lipídica promoveu respostas negativas ao animal. Nesse contexto, foi possível observar no presente estudo que o acréscimo de $7 \%$ de óleo de soja não foi prejudicial à degradação e, consequentemente, a digestibilidade ruminal, uma vez que a adição de óleo de soja não afetou nenhum dos parâmetros avaliados. A maioria dos trabalhos pesquisados sobre o uso de lipídios saturados e insaturados tem demonstrado pequenos ou insignificantes efeitos sobre os parâmetros ruminais. Vargas et al. (2002) ao avaliarem a adição de grão de soja moído e óleo de soja nos níveis de 3 e $7 \%$ na ração de vacas leiteiras, concluíram que as fontes lipídicas reduziram em $20 \%$ o consumo de matéria seca sem, contudo, afetar a produção e composição do leite e os parâmetros fermentativos ruminais. Bettero et al. (2013) avaliaram diferentes fontes lipídicas, entre elas o óleo de soja, e concluíram que a suplementação da dieta com fontes lipídicas na forma livre, inerte, ou parcialmente protegida, ao nível de aproximadamente $5 \%$ da matéria seca, não alteram os parâmetros de cinética de trânsito de partículas do volumoso e do concentrado e a degradação in vitro da FDN.

\section{Conclusão}

A suplementação com concentrado com ou sem a inclusão de $7 \%$ de óleo de soja na dieta de novilhas não afeta a degradabilidade da MS, FDN e FDA do capim Marandu.

\section{Agradecimentos}

Ao Conselho Nacional de Desenvolvimento Científico e Tecnológico - CNPq, pela assistência financeira (processo número 478318 / 2013-8).

\section{Referências Bibliográficas}

AFRC. 1993. Energy and protein requirements of ruminants. Agricultural And Food Research Council, Cambridge. 
Araújo, R. A., Rodrigues, R. C., Santos Costa, C., Santos, F. N. S., Costa, F. O., Lima, A. J. T., Silva, I. R. \& Rodrigues, M. M. 2016. Composição químico-bromatológica e degradabilidade in situ de capim-Marandu em sistemas silvipastoris formados por babaçu e em monocultivo. Revista Brasileira de Saúde e Produção Animal, 17, 401-412.

Berchielli, T. T., Pires, A. V. \& Oliveira, S. G. 2011. Nutrição de Ruminantes. FUNEP, Jaboticabal, Brazil.

Bettero, V. P., Gandra, J. R., Nunes, H. V. N., Freitas, J. E., Barletta, R. V., Carvalho, M. V., Detmann, E. \& Pereira, J. C. 2013. Sources of omega-6 fatty acids do not alter the rumen degradation and transit of fibre from dairy cow diets. Journal of Animal and Feed Sciences, 22, 295-301.

Casali, A. O., Detmann, E., Valadares Filho, S. C., Pereira, J. C., Henriques, L. T., Freitas, S. G. \& Paulino, M. F. 2008. Influência do tempo de incubação e do tamanho de partículas sobre os teores de compostos indigestíveis em alimentos e fezes bovinas obtidos por procedimentos in situ. Revista Brasileira de Zootecnia, 37, 335-342.

Costa, N. L., Monteiro, A. L. G., Silva, A. L. P., Moraes, A., Giostri, A. F., Stivari, T. S. S., Gilaverte, S., Baldissera, T. C. \& Pin, E. A. 2015. Considerações sobre a degradação da fibra em forragens tropicais associada com suplementos energéticos ou nitrogenados. Archivos de Zootecnia, 64, 31-41.

Detmann, E., Souza, M., Valadares Filho, S., Queiroz, A., Berchielli, T., Saliba, E., Cabral, L. S., Pina, D. S., Ladeira, M. \& Azevedo, J. 2012. Métodos para análise de alimentos. Suprema, Minas Gerais.

Ghasemzadeh-Nava, H., Fatahnia, F., Nikkhah, A. \& Zamiri, M. J. 2011. Effects of dietary polyunsaturated fatty acids on ovarian function and prostaglandin secretion in lactating dairy cows. Iranian Journal of Veterinary Medicine, 5, 129-135.

Goes, R. H. T. B, Tramontini, R. C. M., Cardim, S. T, Almeida, G. D., Ribeiro, J., Morotti, F., Oliveira, L. A. \& Brabes, K. C. S. 2012. Degradação ruminal da matéria seca e de proteína bruta de volumosos para bovinos. Revista Acadêmica de Ciências Agrárias e Ambientais. Curitiba, 10, 285-291.
Kozloski, G. V. 2011. Bioquímica dos ruminantes, 3a Ed. edn. Editora Universidade Federal de Santa Maria, Santa Maria.

Mehrez, A. Z., Ørskov, E. R. \& McDonald, I. 1977. Rates of rumen fermentation in relation to ammonia concentration. British Journal of Nutrition, 38, 437-443.

Moreira, G. R., Saliba, E. O. S., Maurício, R. M., Sousa, L. F., Figueiredo, M. P., Gonçalves, L. C. \& Rodriguez, N. M. 2009. Avaliação da Brachiaria brizantha cv. marandu em sistemas silvipastoris Evaluation of Brachiaria brizantha $\mathrm{cv}$. marandu in silvopastoral systems. Arquivo Brasileiro de Medicina Veterinária e Zootecnia, 61, 706-713.

NRC. 2001. Nutrient Requirements of Dairy Cattle, 7th rev. edn. Natl. Acad. Press, Washington, DC., Washington.

Ørskov, E. R. \& McDonald, I. 1979. The estimation of protein degradability in the rumen from incubation measurements weighted according to rate of passage. The Journal of Agricultural Science, 92, 499-503.

Prohmann, P. E. F., Branco, A. F., Paris, W., Barreto, J. C., Magalhães, V. J. A., Goes, R. H. T. B. \& Oliveira, M. V. M. 2012. Método de amostragem e caracterização química da forragem consumida por bovinos em pasto consorciado de aveia e azevém. Arquivo Brasileiro de Medicina Veterinária e Zootecnia, 64, 953-958.

Reis, R. A., Ruggieri, A. C., Casagrande, D. R. \& Páscoa, A. G. 2009. Suplementação da dieta de bovinos de corte como estratégia do manejo das pastagens. Revista Brasileira de Zootecnia, 38, 147-159.

Rodrigues, A. L. P., Sampaio, I. B. M., Carneiro, J. C., Tomich, T. R. \& Martins, R. G. R. 2004. Degradabilidade in situ da matéria seca de forrageiras tropicais obtidas em diferentes épocas de corte In situ dry matter degradation of tropical forages harvested at different ages. Arquivo Brasileiro de Medicina Veterinária e Zootecnia, 56, 658-664.

Salla, L. E., Fischer, V., Ferreira, E. X., Moreno, C. B., Junior, W. S. \& Duarte, L. A. 2003. Comportamento ingestivo de vacas Jersey alimentadas com dietas contendo diferentes fontes de gordura nos primeiros 100 dias de lactação. Revista Brasileira de Zootecnia, 32, 683-689.

SAS. 2004. SAS/STAT User guide, Version 9.1.2. SAS Institute Inc, Cary, NC, USA. 
Sniffen, C. J., O'Connor, J. D., Van Soest, P. J., Fox, D. G. \& Russell, J. B. 1992. A net carbohydrate and protein system for evaluating cattle diets: II. Carbohydrate and protein availability. Journal of Animal Science, 70, 3562-77.

Valadares Filho, S. C., Costa e Silva, L. F., Gionbelli, M. P., Rotta, P. P., Marcondes, M. I., Chizzotti, M. L. \& Prados, L. F. 2016. Exigências nutricionais de zebuínos puros e cruzado - BR-Corte. Universidade Federal de Viçosa, Viçosa, Minas Gerais.

Van Soest, P. J. 1994. Nutritional ecology of the ruminant. Cornell University Press, Ithaca, NY, USA.
Vargas, L. H., Lana, R. P., Jham, G. N., Santos, F. L., Queiroz, A. C. \& Mancio, A. B. 2002. Adição de lipídios na ração de vacas leiteiras: parâmetros fermentativos ruminais, produção e composição do leite. Revista Brasileira de Zootecnia, 31, 522-529.

Article History:

Received 15 December 2017

Accepted 31 January 2018

Available online 27 march 2018

License information: This is an open-access article distributed under the terms of the Creative Commons Attribution License 4.0, which permits unrestricted use, distribution, and reproduction in any medium, provided the original work is properly cited. 